Portland State University

PDXScholar

\title{
Mapping Meaningful Places on Washington's Olympic Peninsula: Toward a Deeper Understanding of Landscape Values
}

\author{
Lee Cerveny \\ US Forest Service Pacific Northwest Research Station \\ Kelly Biedenweg \\ Oregon State University \\ Rebecca J. McLain \\ Portland State University, mclainrj@pdx.edu
}

Follow this and additional works at: https://pdxscholar.library.pdx.edu/iss_pub

Part of the Geographic Information Sciences Commons, Natural Resources Management and Policy Commons, and the Sustainability Commons

Let us know how access to this document benefits you.

\section{Citation Details}

Cerveny, Lee; Biedenweg, Kelly; and McLain, Rebecca J., "Mapping Meaningful Places on Washington's Olympic Peninsula: Toward a Deeper Understanding of Landscape Values" (2017). Institute for Sustainable Solutions Publications and Presentations. 111.

https://pdxscholar.library.pdx.edu/iss_pub/111

This Article is brought to you for free and open access. It has been accepted for inclusion in Institute for Sustainable Solutions Publications and Presentations by an authorized administrator of PDXScholar. Please contact us if we can make this document more accessible: pdxscholar@pdx.edu. 


\title{
Mapping Meaningful Places on Washington's Olympic Peninsula: Toward a Deeper Understanding of Landscape Values
}

\author{
Lee Karol Cerveny $\mathbb{D}^{1} \cdot$ Kelly Biedenweg $^{2} \cdot$ Rebecca McLain $^{3}$
}

Received: 22 August 2016 / Accepted: 27 May 2017

(C) Springer Science+Business Media New York, LLC (outside the USA) 2017

\begin{abstract}
Landscape values mapping has been widely employed as a form of public participation GIS (PPGIS) in natural resource planning and decision-making to capture the complex array of values, uses, and interactions between people and landscapes. A landscape values typology has been commonly employed in the mapping of social and environmental values in a variety of management settings and scales. We explore how people attribute meanings and assign values to special places on the Olympic Peninsula (Washington, USA) using both a landscape values typology and qualitative responses about residents' placerelationships. Using geographically referenced social values data collected in community meetings $(n=169)$, we identify high-frequency landscape values and examine how well the landscape values are reflected in open-ended descriptions of place-relations. We also explore the various interpretations of 14 landscape values used in the study. In particular, we investigate any overlapping meanings or blurriness among landscape values and reveal potentially emergent landscape values from the qualitative data. The results provide insights on the use of landscape values mapping typologies for practitioners and researchers engaged in the mapping of social values for PPGIS.
\end{abstract}

Lee Karol Cerveny

lcerveny@fs.fed.us

1 US Forest Service, Pacific Northwest Research Station, 400 N. 34th St., Suite 201, Seattle, WA 98103, USA

2 Department of Fisheries \& Wildlife, Oregon State University, 154 Nash Hall, Corvallis, OR 97331-3803, USA

3 Institute for Sustainable Solutions, Portland State University, Mail code: SUST, P.O. Box 751, Portland, OR 97207, USA
Keywords Participatory GIS · Landscape values • Qualitative

\section{Introduction}

Unraveling the complex web of associations people have with natural places is an important goal of land managers charged with making decisions about how resources are governed and used (Williams et al. 2013; Yung et al. 2003). Landscapes embody a variety of symbolic meanings and practical benefits for people. Landscapes are defined by their geo-physical attributes and social constructions as people assign values or attach meanings to places (Stedman 2003; Ardoin 2014; Tuan 1977). Meanings are formed both through direct personal or collective experiences of a place or the rendering of stories or histories about a place (Zube 1987). Meanings people attach to places can be influential in the process of identity-creation as well as community formation (Kil et al. 2014; Scannell and Gifford 2010). Bound up in place meanings are a mix of commodity and non-commodity values (Cheng et al. 2003). Methods in public participatory GIS (PPGIS) are becoming widely used to engage people in identifying the spatial dimensions of social, cultural, spiritual, and psychological relationships with landscapes for use in planning and management (Ives and Kendal 2014).

PPGIS tools are increasingly common in environmental planning and management efforts at a variety of spatial scales, management, contexts, and settings (Brown and Kyttä 2014). PPGIS approaches have been used in recent years to explore both the benefits or values people gain from landscapes as well as the meanings they derive from 
landscape interactions. Using maps, aerial photographs, and other spatial images, participants identify and describe meaningful places on the landscape and provide information that elucidates their multiple connections with places and the variety of landscape interactions (McLain et al. 2013). Spatial images are used as a means to gather perceptions of landscape values, benefits, and preferences by asking participants to draw and label shapes or place dots that represent particular values (McLain et al. 2013). PPGIS has been used to capture social or landscape values (Alessa et al. 2008; Beverly et al. 2008; Brown 2004; Brown and Alessa 2005; Brown and Raymond 2007; Brown and Reed 2009; Brown and Weber 2012; Clement and Cheng 2011; Nielsen-Pincus 2011; Sherrouse et al. 2011; Zhu et al. 2010), landscape or development preferences (Brown 2006; Brown and Weber 2012; Brown et al. 2014; Raymond and Brown 2010), ecosystem services (Brown et al. 2012, 2015; Brown and Fagerholm 2015; Rall et al. 2017; Raymond et al. 2009; Sherrouse et al. 2011; Fish et al. 2016), city parks (Brown et al. 2014; Tyrväinen et al. 2007), climate change risk (Raymond and Brown 2010; 2011), environmental conflict (Brown and Raymond 2014; Brown et al. 2014; Moore et al. 2017) to name a few. Once gathered for the study population, data are digitized, aggregated, disaggregated, and spatially analyzed. Spatial outputs generated by this technique demonstrate how values are distributed across the landscape, depict overlapping values, and show "hotspots" of high-density values for particular sites (Alessa et al. 2008; Brown 2017). Socio-spatial layers can be integrated with biophysical data and applied to environmental planning (Whitehead et al. 2014). For PPGIS approaches, there have been variations in data gathering approaches, such as map materials (paper, digital), image type (maps, aerial photos), data collection tools (household survey, interviews, focus group, community workshop), geometries (points/dots, lines, polygons), and social interactions (individual-based, group oriented, consensus-based) (Brown and Kyttä 2014; McLain et al. 2013). Technological upgrades have allowed PPGIS to be done using Voluntary Geographic Information systems, where non-experts contribute to databases and share information voluntarily using personal data devices (Brown 2017) as well as with crowdsourcing approaches used for conservation planning (Brown et al. 2015). Moreover, PPGIS approaches have been blended with deliberative value formation models to elicit shared values (Kenter et al. 2016; Raymond and Kenter 2016). The variety of approaches to participatory mapping and its many applications have been well synthesized (Brown and Kyttä 2014; McLain et al. 2013; Sieber 2006).

Values are central to the management of ecological systems and values have been conceptualized in various ways. Early research on values in resource management distinguished between held and assigned values, where held values were seen as guiding principles or core beliefs that shape judgments and actions and transcend specific situations (Rokeach 1973). Assigned values measure the relative worth of something and are attached to objects or physical places (Bengston et al. 1999; Brown 1984; Lockwood 1999; Seymour et al. 2010). Whereas held values were deemed more inscrutable, assigned values may fluctuate depending on external factors and conditions (Brown 1984). The relationship between held values and assigned values has not been fully explored (Winter 2005), though it is believed that held values influence assigned values (Brown 1984; Lockwood 1999). Building from the Rokeach framework, Schwartz and Bilsky (1987) identified transcendental values as guiding principles and conceptions about desirable end states or behaviors that transcend specific situations and guide choices or justify actions. Transcendent values permeate socio-cultural institutions and provide structure from which people within a culture frame their lives. The array of 10 values categories identified by Schwartz and Bilsky (1987) is thought to be universal across cultures, although each cultural system may vary in its emphasis on particular value sets (Raymond and Kenter 2016). Moreover, transcendental values are thought to influence environmental behavior (Stern and Dietz 1994; Schultz et al. 2005). More recently, scholars exploring cultural ecosystem services distinguish between transcendent values, contextual values, (ones' opinions about the relative worth of something, which could be both held and assigned), and value indicators (the actual worth expressed in monetary terms), which is akin to Rokeach's notion of assigned values (Kenter et al. 2015, 2016; Raymond and Kenter 2016).

Rolston and Coufal (1991) developed a set of 10 values that integrated human and biotic values: life support, economic, scientific, recreation, esthetic, wildlife, biotic diversity, natural history, spiritual, and intrinsic. Bengston and Xu (1995) offered a values typology that divided values into instrumental (meeting human needs) and noninstrumental (valued for its own worth). Bengston and $\mathrm{Xu}$ (1995) argued that Rolston and Coufal's typology included non-exclusive categories and mixed abstract values (how we care about things) with "objects of value," (what we care about), such as recreation, wilderness, and biodiversity. Brown and Reed (2000) built a landscape values typology derived from work of Rolston and Coufal (1991). They defined 13 landscape values: economic, learning, historic, cultural, future, intrinsic, spiritual, therapeutic, subsistence, life supporting, biodiversity, recreation, and esthetic, and asked respondents to place colored dots on a map for each value. Brown and Reed (2000) validated their landscape values typology by demonstrating that each landscape value represented a discrete construct, and that the values could not be organized into higher order factors. They also 
confirmed that participants understood the typology and used all of its elements in mapping. The authors found all landscape values to be useful (with $25 \%$ of respondents utilizing the least popular value on the list). The study also showed that respondents were as likely to select noncommodity values (esthetic, spiritual) as commodity values (economic, subsistence). The typology was based on the transactive nature of human-environment interactions, where humans are cognizant actors who experience the landscape directly through their senses, and assign meaning to places based on these experiences (Zube 1987). The assigning of landscape values to a map requires that the respondents recall their experiences and the meanings generated by that experience, which are influenced by held values.

The landscape value typology developed has been applied in a wide variety of countries, spatial scales, and socio-cultural settings and has achieved some level of standardization through replication (Alessa et al. 2008; Reed and Brown 2003; Brown and Reed 2009; Brown 2012, 2008, 2006; Brown and Weber 2011; Brown et al. 2015; Raymond and Brown 2007: Raymond and Brown 2010; Clement and Cheng 2011; Fagerholm et al. 2012; Beverly et al. 2008; Nielsen-Pincus 2011; Raymond et al. 2007; Sherrouse et al. 2011; Tyrväinen et al. 2007). The landscape values typology is commonly used in conjunction with spatial attributes mapping (Brown 2004) where participants have options to assign multiple values across a landscape (using points or drawing shapes). Across the studies, there has been fairly consistent application of the original 13 landscape values, with some customization to suit socio-cultural or biophysical conditions. For example, in Alaska, the value 'subsistence' was used, because of the cultural, political, and economic importance of food gathering as cultural practice (Alessa et al. 2008), but this has not been uniformly applied in other studies. Another value that has been sometimes added is 'wilderness,' which is appropriate in Euro-American settings, but is less meaningful in non-Western societies (Brown and Alessa 2005). Several studies employing the landscape values typology have included "special places" as an additional mapped feature, often designated with a special symbol (X) and described using narrative description. (See Brown and Kyttä 2014 for a comprehensive overview of existing PPGIS studies).

Despite changes in technology and advances in sociospatial analysis, the landscape values typology has remained relatively constant. Since the original testing (Brown and Reed 2000), discussion about the values categories, meanings, or their interpretation has been limited to individual studies. Beverly et al. (2008) conducted testing of values categories in the typology by asking respondents to identify areas of overlap, redundancy, or values that had been omitted, as well as values that would not manifest easily on a physical landscape. This pre-testing resulted in the combining of "cultural" and "historical" into one value. The value "future" was deemed difficult to associate with specific landscape features and was removed. "Therapeutic" was considered to be overlapping with several others (recreation, spiritual, esthetic). Life sustaining was omitted because it was difficult to discern in a landscape dominated by forest, where everything could be considered lifesustaining. Other studies have explored the utility of the landscape values typology to understand humanenvironment relationships. Brown and Brabyn (2012) used the landscape values typology to explore which values related best to particular landscape features as a way to learn whether there are intrinsic relationships between landscape values and physical features. Brown and Weber (2012) explored whether landscape values are changeable over time for a study population and found consistency in the frequency and spatial distribution of values over a 6 year period. Brown and Raymond (2007) used the landscape values typology to explore which landscape values were best predictors of place attachment.

Landscape values are understood as a "relationship value" that bridges held and assigned values (Brown and Weber 2012). By associating meanings with a physical place, what is personally meaningful becomes interwoven with notions of what is important to that person about the physical landscape. So, when doing PPGIS, participants draw upon held values in the process of assigning values to landscapes (Brown and Donovan 2014; Brown and Weber 2012). The assignment of predefined landscape values to places on a map assumes that values can be readily understood as discrete (Brown 2004). The approach also assumes a shared understanding about the meaning of these landscape values for a particular socio-cultural group. Despite the fact that landscape values are specifically defined for participants, interpretations of each landscape value in the typology may vary. The approach also relies on the participant's ability to associate predefined values with a set of lived experiences, memories, or encounters of a particular geographic place, and tie that place to a symbolic representation of that place (i.e., map, photograph) (Brown and Kyttä 2014; Gustafson 2001; Zube 1987). Brown (2012) noted the cognitive challenges for the mapping participants to identify locations on maps and assign meanings based on experience. Some of these assumptions have yet to be fully explored, despite the fact that the landscape values approach has been standardized. A better understanding of the landscape values typology may help PPGIS researchers to interpret their results.

We rely on data gathered in eight community meetings on the Olympic Peninsula (Washington, USA) $(n=169)$ to explore aspects of the landscape values typology. Data were 
gathered as part of a series of public forums held throughout the study area. Although a group table formation was used to present a shared map, the study did not utilize a deliberative model where group discussion occurred around the participatory mapping exercise (Kenter et al. 2016; Raymond and Kenter 2016). The mapping was wholly individualistic and results reflect individual values. We customized Brown and Reed's (2000) original landscape values typology to suit the social landscape in our study area. Our study deviated from standard spatial attributes mapping approaches that assign multiple values across the landscape (Brown 2004). Instead, we emphasized identification of a prescribed number of "special places" and asked participants to assign individual landscape values to those places. Respondents also provided narrative description about their relationship to that place, which was subsequently coded and analyzed. The combination of data approaches (assigned landscape values and the open-ended responses) provides a unique opportunity to gain more indepth understanding of each individual landscape value to respondents and to assess whether the values are universally or fully understood. We begin to discern the extent to which there is shared understanding of the value, whether the value encompasses a discrete category (or if overlaps exists with other values). And, the rich trove of place-based narrative data allows us to explore the potential for new values to emerge. Our contribution is to offer a magnified view of the values in the typology and learn how respondents relate to those values differently. Themes unearthed from the narrative descriptions reveal important insights about the landscape values categories and suggest emergent values to be considered for inclusion in future values mapping efforts.

\section{Methods}

\section{Study Context}

The Olympic Peninsula is a predominantly rural area in western Washington that encompasses four counties (Jefferson, Clallam, Mason, and Grays Harbor) (Fig. 1). The area is 5648 square miles and extends from the Pacific Ocean to the Hood Canal. The Strait of Juan de Fuca forms the international border with Canada. The southern region is bounded by Grays Harbor and the Chehalis River. The region is dominated by old growth temperate rainforest, glaciated peaks, remote coastal beaches, and a dozen salmon-bearing river systems. Native American tribes living along the rivers and coastlines were met by Spanish explores in the 18th century and European settlers and farmers in the 19th century. The 20th century was dominated by logging and commercial fishing. The area is sparsely populated with 234,772 inhabitants (U.S. Census 2010) and is home to eight officially recognized tribes.

Land ownership in the region is complex and the area's contested environmental history has been well-documented. (Lien 1991). The area includes the Olympic National Park, which is both a World Heritage Site and United Nations International Biosphere Reserve. Surrounding the park is the Olympic National Forest, founded in 1907 as a forest reserve and now managed for multiple uses, including logging, special forest products, and recreation. The executive decisions establishing these federal lands contributed to distrust of federal land management agencies. In the 1990s, these conflicts came to the forefront, as citizens fought over the protections required for endangered species whose habitat was potentially threatened by logging activity. Subsequent declines in timber production led to job loss and out-migration (Buttolph et al. 2006). The Olympic Peninsula is a popular visitor destination for international travelers as well as residents of the Seattle metropolitan area (population 3.7 million, 2014). In recent years, the area has seen a proliferation of retirees, second home owners, telecommuters, and weekend cabins. Because of this diversity, the Olympic Peninsula represents an ideal setting for conducting a study of natural resource values and place attachments.

\section{Study Approach}

Olympic National Forest officials sought to identify special places on the Olympic Peninsula and the values and meanings associated with those places for future use in forest planning efforts. The study incorporated a public meeting model which fulfilled the needs of forest managers to engage the public around forest and resource management. As Brown and Kyttä (2014) note, PPGIS is often a tug of war between GIS and pubic engagement. Resource managers view public events as means to enhance rapport and build trust, while also gathering information that can be used for decision-support. The public meeting format was deemed ideal for achieving these mutual goals. Previous studies incorporating a community meeting format had been utilized elsewhere with success (Raymond and Brown 2011), although our approach varied from recent workshop formats that utilize a deliberative model for eliciting values (Raymond and Kenter 2016). A combination of purposive and referral sampling approaches were used to reach potential participants. Key stakeholders were recruited using established resource agency lists and publicly available contact lists for organized groups. Other local residents were recruited through traditional media announcements, list-serves, and word-of-mouth strategies. The intent was to maximize the diversity of relevant stakeholders for each public mapping event. Since random sampling strategies 


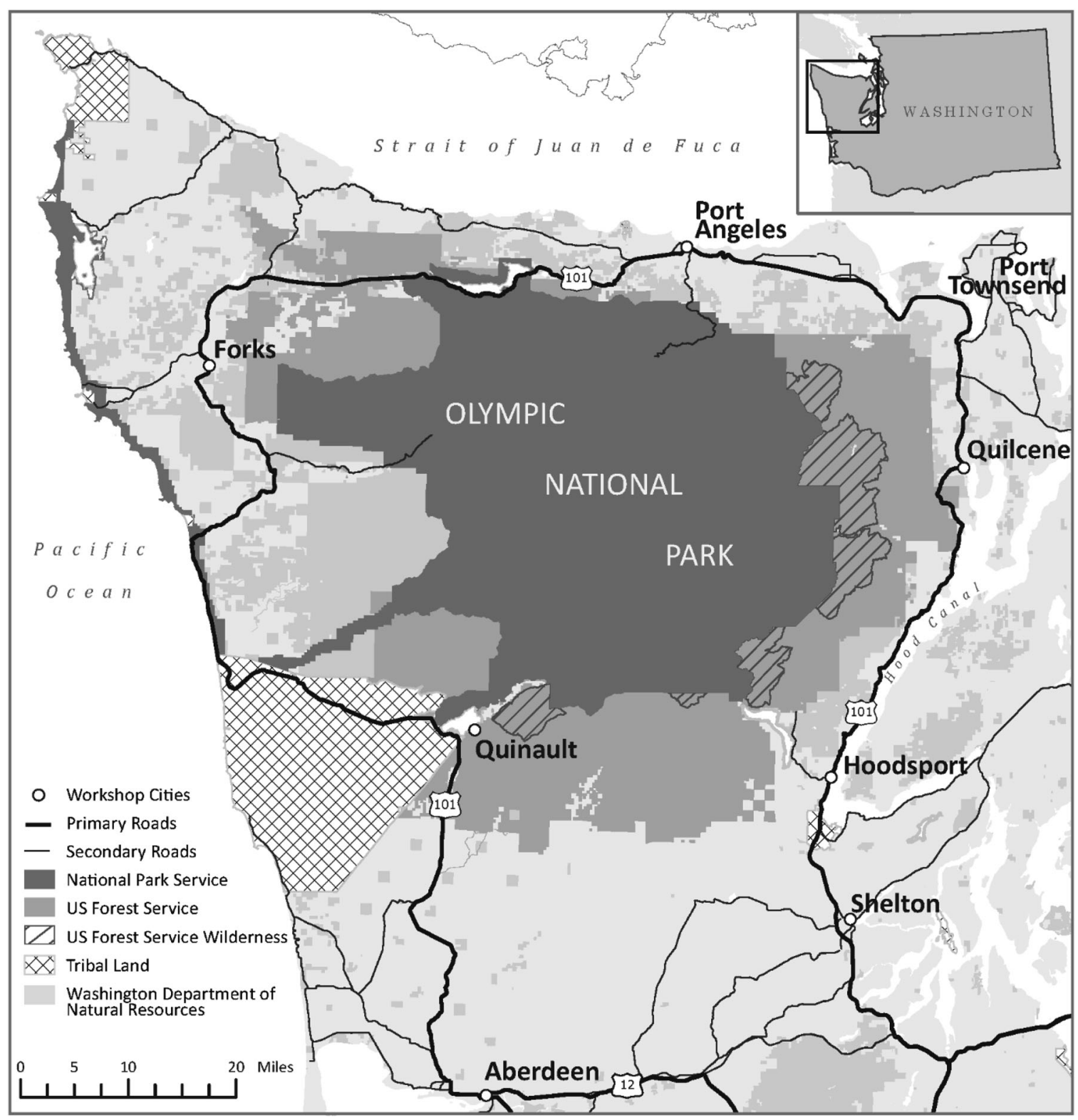

Fig. 1 Map of the study area: Olympic Peninsula, WA

were not utilized, study findings are not generalizable beyond the study population.

\section{Public Meeting Protocol}

Participatory mapping events were conducted in eight communities around the Olympic Peninsula over the course of 2011 and 2012: Quilcene, Hoodsport, Shelton, Aberdeen, Lake Quinault, Forks, Port Angeles, and Port Townsend. A total of nine mapping events were held, with one community hosting two events due to low turnout. In total, there were 169 participants, with an average of 21 per community. Attendees represented a range of stakeholder groups and interests (forest products, tourism, conservation, active recreation) and tended to be highly interested in the affairs of the US Forest Service. Mapping events were $90 \mathrm{~min}$ in length. Tables were arranged in small group clusters, with 4 to 6 participants gathered at each table. A large map of the Olympic Peninsula $\left(91 \mathrm{~cm}^{2}\right)$ was affixed in the middle of the table and covered with a sheet of heavy plastic. The participants partook in two distinct mapping exercises that were $30 \mathrm{~min}$ each ("special places mapping" and "resource activities mapping") and completed a demographic worksheet. The meeting concluded with a group discussion of participants' reactions to the mapping activities and insights from their table group.

For the special places mapping exercise, participants were given a laminated sheet with a list of 14 landscape 
Table 1 Landscape value definitions

\begin{tabular}{|c|c|}
\hline Landscape value & Definition \\
\hline Esthetic & I value this place for the scenery, sights, smells or sounds. \\
\hline Economic & $\begin{array}{l}\text { I value this place because it provides income and employment opportunities through industries such as forest products, } \\
\text { mining, tourism, agriculture, shellfish, or other commercial activity. }\end{array}$ \\
\hline Environmental quality & $\begin{array}{l}\text { I value this place because it helps produce, preserve, and renew air, soil and water or it contributes to healthy habitats for } \\
\text { plants and animals. }\end{array}$ \\
\hline Future & I value this place because it allows future generations to know and experience as it is now \\
\hline Health & I value this place because it provides a place where I or others can feel better physically and/or mentally \\
\hline Heritage & $\begin{array}{l}\text { I value this place because it has natural and human history that matters to me and it allows me to pass down the wisdom, } \\
\text { knowledge, traditions, or way of life of my ancestors }\end{array}$ \\
\hline Home & I value this place because it is my home and/or I live here \\
\hline Intrinsic & I value this place because it exists, no matter what I or others think about it or how it is used \\
\hline Learning & I value this place because it provides a place to learn about, teach, or research the natural environment \\
\hline Recreation & I value this place because it provides outdoor recreation opportunities or a place for my favorite recreation activities \\
\hline Social & $\begin{array}{l}\text { I value this place because it provides opportunities for getting together with my friends and family or is part of my } \\
\text { family's traditional activities }\end{array}$ \\
\hline Spiritual & I value this place because it is sacred, religious, or spiritually special to me \\
\hline Subsistence & I value this place because it provides food and other products to sustain my life and that of my family \\
\hline Wilderness & I value this place because it is wild \\
\hline
\end{tabular}

values and definitions and the values were posted on a large screen (Table 1). This landscape values typology utilized was adapted from Brown and Reed (2000). The value "home" was added to the list to indicate a sense of belonging to a place. The values "life sustaining" and "biological" were combined and listed as "environmental quality." Our value "heritage" combined categories of "cultural" and "historic." Finally, "health" was added to recognize the importance of natural places enhancing physical or emotional well-being. The meeting facilitator recited the full list of landscape values and their definitions prior to the mapping component. For this exercise, participants were asked to identify five places on the Olympic Peninsula that were meaningful or important to them. For each place, they selected from the typology a primary value that was most important and wrote this value in a response box. They were then asked to identify "other values" associated with this place. There was no limit on the number of values they could write, although the response space was confined, potentially making it difficult to enter all 14 values. In addition to assigning values, participants were asked the following. (a) Why do you value this place? (b) What activities do you do in this place? There was enough space to compose a short paragraph for each of these prompts, but most respondents wrote one or two phrases or sentences, or a string of descriptors to acknowledge their associations with that place. Once the worksheet was completed, participants used colored permanent markers to draw on the maps using fixed points, lines; or polygons of any size or shape. Each mapped item was associated with the worksheets using a simple numerical coding system. The second mapping activity focused on resource uses-emphasizing locations of their most prominent outdoor activities and frequency of use. Finally, participants filled out a brief demographic worksheet and submitted all materials to the facilitator (Besser et al. 2014). This paper only refers to data collected in the special places exercise.

This approach deviates from many traditional PPGIS studies that use landscape values typology to attach multiple values to multiple places on a landscape using a set of weighted or unweighted colored dots (or markers) - about 4 to 6 dots per landscape value (Brown and Reed 2000, 2009; Brown 2004; and many others). In many traditional PGIS studies, special places were indicated as a separate feature with open-ended prompts. Our study was designed to emphasize special places and to learn as much as possible about them (locations, landscape values, and narrative description). We were less interested in assigning an array of values to a landscape and more interested in mapping special places and understanding their values and meanings to local residents. Our methodological approach recognizes that individuals hold multiple values for a particular place simultaneously. By distinguishing between primary value and secondary values, we urged respondents to prioritize the meaning of that place to them in relation to other values. This prioritization elevated the most prominent landscape value associated with a particular place, which made it possible to examine the accompanying narrative description attached to that place for evidence of that primary value through coding. By allowing respondents to add additional values, our method recognized the array of values attached to a place. 
The group-table design feature was intentional, since one of the project goals was to encourage interaction. It also was a convenient way for the study team to gather information from multiple participants. The meeting format did not include specific group discussion questions or encourage organized group deliberation. The exercises were designed to be individual activities, where participants marked individual patterns on a shared map and wrote their own personal responses to prompts on their own worksheet (not shared). For each mapped object, participants noted associated resource activities, assigned landscape values, and elucidated place-meanings. The small tables appeared to make the activity more enjoyable for participants and resulted in casual conversation. We commonly observed instances of participants assisting each other with wayfinding or recalling the names of trails, campsites or roads, which seemed helpful and satisfying for participants. The group table format introduces the potential for social desirability bias for the mapping activity, where participants could feel subtle pressure to mark places noted by others at the table or be influenced by pre-existing drawings on the map. Additionally, it is possible that the size of the mapped objects or the geometry choice (point, line, polygon) used by participants could be influenced by what others had drawn on the map. We acknowledge the potential for this bias in the group table format for the mapping component; and, in fact observed occasional instances where participants attempted to influence mapping outcomes of others. As many have previously noted, mapping can be a means of negotiating or demonstrating power relations among stakeholders, especially in conflict situations (Ramirez-Gomez et al. 2016). Future analysis of object size and spatial patterning by table group may illuminate the potential for these biases to occur.

While social desirability bias may influence the mapping component, our analysis here focuses on the landscape values assigned and narrative descriptions offered about each special place. The mapping activities were designed to elicit individual values on a shared mapping platform. Unlike workshop approaches to participatory mapping, a deliberative approach was not used, nor was there an attempt to determine collective values of table participants through negotiation, group prioritization, or other means (Raymond and Kenter 2016). Rather, the group format was a matter of convenience and designed to promote congeniality. Special places attributes were transcribed individually on worksheets and were not indicated on the group map or discussed at the tables. Worksheets were placed in sealed envelopes collected by the study team. We saw no evidence of cooperation among participants in preparing the worksheets. Nor did we provide an opportunity for group discussion of values, activities, and meanings. While we recognize the potential for social desirability bias for the spatial data and acknowledge that the spatial objects mapped may influence the values and activities subsequently revealed, our analysis focuses on the associations between landscape values and landscape meanings garnered through the narrative descriptions. Conducting a table-by-table assessment may reveal a bias based on proximity. But, it's unclear whether or how that potential bias may influence the relationship between the landscape value selected and the meanings elucidated. Since this analysis focuses on qualitative responses and assigned values from the worksheets, we are far less concerned about social desirability effects.

\section{Data Analysis}

The data collected were entered into a comprehensive database that included demographics and data from the mapping worksheets which summarized the landscape values, place names, and qualitative responses. The mapped locations were scanned and digitized to create a series of maps that examined geographic distribution and frequency of mapped places and that explored the distribution of landscape values and resource activities across the Olympic Peninsula landscape. Numerical data were analyzed using Excel and Spss statistical software. Spatial analysis was conducted and details are described elsewhere (McLain et al. 2013). This analysis focuses on comparing narrative descriptions with assigned landscape values and our discussion of the analysis focuses on this aspect only.

To understand more about landscape values and how they are understood by Olympic Peninsula residents, we analyzed the data in the several ways. First, we performed descriptive statistics to assess the frequency of primary and secondary (all other) landscape value associated with all 818 places to get a sense of the overall distribution of values. Next, we examined the dataset for 818 places to explore whether the landscape values assigned to the place were reflected in the qualitative explanation. Some respondents (92) did not provide any narrative description. For the remaining 724 cases where narrative description was provided, we used the landscape values typology (and established definitions) as a guide to determine the meaning of each value. Two independent analysts read each narrative description and assigned a binary response to indicate presence or absence of the primary landscape value's meaning in that individual piece of narrative text. The decision was made based on the meaning of what was written, not the presence of the actual words used in the landscape value. (For example, if a respondent had written, "I enjoy this trail for hiking and mountain biking," and the landscape value "recreation" had been assigned, that would be considered a match and assigned a "1," even though the word "recreation" had not been used. Conversely, if a respondent had assigned a place with the landscape value, "economic" and had 
written, "The views from the ledge are inspirational," this would be assigned a " 0 " (non-match). Two analysts systematically examined each entry and decided either "yes," (assigned a 1) the landscape value was represented in the qualitative response or 'no' (assigned a 0) the value was not directly featured in the explanation. Sometimes the respondent's descriptions were ambiguous, indirect, or not well understood, which meant they were assigned a zero. In the few cases where the two analysts had discrepancies about the presence/absence of a landscape value, the senior researcher made the ultimate decision. Coding the data this way allowed the research team to fully comprehend each text and its meaning. Use of computer-assisted analytical programs to calculate words and determine meanings suggest some efficiencies, but would not allow long strings of qualitative data to be adequately grouped into like constructs.

The rich qualitative data set provides an opportunity to delve more deeply into each individual landscape value in the typology. We analyzed the data set of places where narrative description to the question, "Why do you value this place?" had been offered. These 724 cases were sorted by primary landscape value. For each primary landscape value, we studied the full set of narrative responses. One member of the research team read all responses associated with each landscape value and came up with an initial list of discrete codes and code definitions as a way to label the content. The coding notebook guided all subsequent coding decisions. Next, two independent analysts read each of the narrative responses for all landscape values and assigned one or more codes to each segment of qualitative text captured in the database. This first round of coding identified some additional codes that the study team agreed upon as discrete concepts; and, the coding notebook was revised (total 57 codes). A third round of coding reclassified data with the newly incorporated codes. Discrepancies in coding decisions between the two analysists were noted and differences were discussed until mutual agreement was achieved. Efforts were made to utilize consistent codes used across the landscape values, although not all codes were relevant for all landscape values, and some codes appeared only in association with a single landscape value. In the results section, we present each of the 14 landscape values and describe the range of qualitative responses associated with that value.

\section{Results}

\section{Respondent Characteristics}

Community mapping events were attended by 169 participants who identified 818 special places on the Olympic Peninsula (4.8 places per respondent). On average, respondents were 56 years of age (compared to 47 years for the four-county study area) (U.S. Census 2010). Participants had lived on the Olympic Peninsula for an average of 32 years. Study participants were predominantly male $(58 \%)$.

\section{Assigning Landscape Values}

Research participants attached an average of 2.4 landscape values to each site. "Primary value" refers to the most important value respondent's associated with the special place identified. All respondents provided at least one primary value. "Secondary values" refer to all other values provided in the response box. Figure 2 shows the distribution of primary and secondary values. For primary values,
Fig. 2 Percentage of values for primary values and secondary values (all other values) for all places

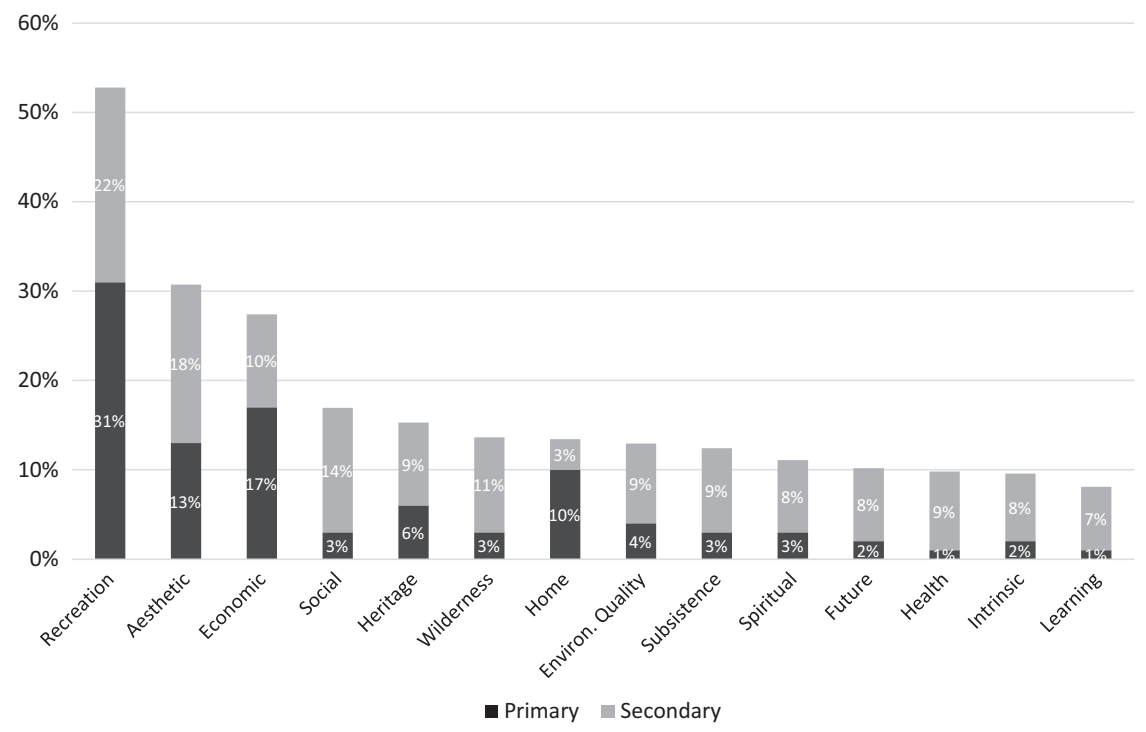


"recreation" was most commonly noted, followed by "economic," "esthetic," and "home," which taken together accounted for $71 \%$ of all primary values. For secondary values, the most prominent were "recreation," "esthetic," "social" and "wilderness" which combined for 73 of all secondary values. The value "home" was prominent as a primary value, but less indicated as a secondary value. In contrast, "social" emerged as more prevalent as a secondary value.

\section{Describing Values Associated with Place}

Before delving into the meanings of landscape values, it is important to understand the extent to which the primary landscape value assigned to a special place was reflected in the narrative description provided by study participants. In total, 1763 landscape values used to describe 724 places (Table 2). We found that the primary landscape value was reflected in the narrative descriptions $74 \%$ of the time. We also broke down responses by each primary landscape value category to observe variation in the degree to which the primary landscape value assigned is reflected in the narrative description. Results suggest that some landscape values are more likely to match with the qualitative response than others. For two landscape values, "social" (91\%) and "wilderness" (92\%), the likelihood of the qualitative response matching the primary landscape value was far greater than the average (73\%). Other values that were more often captured included "economic" and "home." ("Health" was high, but the response rate was too low to judge.) There was far less consistency with "learning" (38\%) and "future," (50\%) although the sample size was small for these two landscape values. "Spiritual" (58\%) also was well below the average. It is worth noting that "recreation" (66\%), the landscape value applied most frequently by respondents, was lower than average.

In the instances where there was no match between primary value and narrative description, the reasons for the discrepancies are varied. In some cases, the narrative description was contained in a secondary value. For example, a respondent indicated Mt. Olympus as their special place and assigned the primary value "esthetic." When asked why they valued this place, they responded simply, "Adrenaline rush." This respondent also applied a secondary value, "recreation" which more aptly captures this explanation. Another respondent selected North Reed Hill as a special place and assigned the primary value "economic" and a secondary value, "subsistence." In response to the question about why they valued this place, the respondent explained, "Folks access the area for firewood, hunting, and fishing." Again, the secondary value more adequately captures this explanation. In 91 cases (13\%), neither primary nor secondary values captured the narrative
Table 2 Presence of landscape values in narrative descriptions for cases where narrative description was offered

\begin{tabular}{|c|c|c|c|}
\hline $\begin{array}{l}\text { Primary value } \\
\text { (V1) }\end{array}$ & $\begin{array}{l}\text { Respondents } \\
\text { who provided } \\
\text { narrative } \\
\text { description }\end{array}$ & $\begin{array}{l}\text { Percent where } \\
\text { V1 observed in } \\
\text { narrative } \\
\text { description }\end{array}$ & $\begin{array}{l}\text { Strength of } \\
\text { linkage }\end{array}$ \\
\hline $\begin{array}{l}\text { All primary } \\
\text { values }\end{array}$ & 724 & $74 \%$ & \\
\hline Wilderness & 24 & $92 \%$ & Very strong \\
\hline Social & 22 & $91 \%$ & Very strong \\
\hline Health & 7 & $86 \%$ & Strong \\
\hline Home & 74 & $85 \%$ & Strong \\
\hline Economic & 130 & $81 \%$ & Strong \\
\hline $\begin{array}{l}\text { Environmetal } \\
\text { quality }\end{array}$ & 23 & $78 \%$ & Medium \\
\hline Intrinsic & 16 & $75 \%$ & Medium \\
\hline Subsistence & 20 & $75 \%$ & Medium \\
\hline Esthetic & 99 & $74 \%$ & Medium \\
\hline Heritage & 47 & $66 \%$ & Weak \\
\hline Recreation & 212 & $66 \%$ & Weak \\
\hline Spiritual & 26 & $58 \%$ & Very weak \\
\hline Future & 14 & $50 \%$ & Very weak \\
\hline Learning & 8 & $38 \%$ & Very weak \\
\hline
\end{tabular}

Linkages: Very strong: >90\%, Strong: 80-89\%; Medium: 70-79\%; Weak: $60-69 \%$; Very weak: $<60 \%$

description. We reviewed the instances where there was no match-up between any values (primary or secondary) and the narrative description to see if there were any patterns. For those mismatched cases, the most common primary value was "recreation" (38), followed by "esthetic" (12), and "heritage" (9). For example, a respondent marked Lake Ozette as a special place and listed the values, "recreation" and "spiritual." Their open-ended explanation said, "Stunning! Magnificent! Petroglyphs and bears." This phrase was coded by the researchers as "beauty," "culture," and "special feature." In that case, it appeared that the respondent had multiple values for that site and the values selected were not included in the response. In reviewing cases where no values were represented, there is a sense that respondents may have believed that the simple listing of landscape values was enough to explain their relationship with the place, and they used the open-ended prompt to make an additional statement about the place that they wanted land managers to hear. For example, a respondent marked a road to the Staircase trailhead and labeled it with the primary value, "learning" and a secondary value, "spiritual." The explanation provided appeared to be a political statement, "Many (thousands) of people going there. But, the road is not in good shape. The value of setting does not approach value of park." We also noticed that there were 18 respondents who were responsible for multiple "mismatches" in the mapping exercises, with some as many as 3 or 4 . This 
suggests that there may idiosyncratic examples where certain respondents have a propensity to list landscape values that are different from their narrative description.

An important caveat to this analysis is the way the openended values question was framed. The worksheet asked, "Why do you value this place?", which elicited responses that may or may not echo the actual landscape value assigned. Participants were not asked, "Why did you assign this particular landscape value to this place?" which may have generated responses more directly related to the landscape value chosen.

\section{Landscape Values Content Analysis}

We analyzed the full set of narrative descriptions used by respondents to the question, "Why do you value this place?" Narrative descriptions provided in the response box ranged in length and specificity. Some wrote detailed paragraphs about their place connections, memories, and symbolic meanings. Others jotted down key words, or wrote nothing at all. We explore each of the 14 landscape values in order of frequency. Responses were coded, with no limits to the maximum number of codes per segment. Direct quotes illustrate the themes that emerged. The accompanying tables show the top-10 thematic codes used for each landscape value in descending order. (For values with low sample size the top-lists are truncated.)

\section{Recreation}

We used 42 thematic codes for descriptions assigned the primary landscape value "recreation,", which suggests high diversity (Table 3). Descriptions of places labeled "recreation" typically involved outdoor activities (e.g., hiking, climbing, or ATV riding). An Aberdeen participant described one place: "The area has some of the southern Olympic's last old-growth stands and is an excellent place to hike, boat and just casually visit for its scenic beauty." "Access" or being able to get to places near home or close to a major highway came up frequently in the narrative. One participant enjoyed a beach because it was, "Scenic, close to home, unique environment, accessible, good for family/ friends." Other themes that came up frequently were both "hunting and fishing" as well as "harvest," which indicates that for many, provisioning activities are both discretionary and necessary. Here, "recreation" intersects with the value "subsistence." As this Lake Quinault participant explained, "It's a place I've spent time hunting with friends and family off the grid." Recreation also had an esthetic component, with emphasis on "natural beauty," and "scenery." "It's a gorgeous hike, the valley is enchanted!! Especially when shared with people you love!" Many participants described places to be with their children, extended family or their
Table 3 Top 10 codes and associated landscape values for "Recreation" and "Economic"

\begin{tabular}{lcl}
\hline Code name & Frequency & Associated landscape values \\
\hline Recreation & & \\
Outdoor activity & 98 & Recreation \\
Access & 65 & \\
Hunt-fish & 52 & Subsistence; Recreation \\
Beauty & 39 & Esthetic \\
Family & 34 & Social \\
Harvest & 32 & Subsistence \\
Friends & 29 & Social \\
Scenery & 28 & Esthetic \\
Special feature & 23 & \\
Water & 16 & Environmental quality \\
Beach food & 16 & Subsistence \\
All others & 148 & \\
Total & 580 & \\
Economic & & \\
Work & 47 & Economic \\
Logging & 428 & Economic \\
Community & 17 & Social \\
Overall economy & 24 & Economic \\
Tourism & 22 & Economic \\
Hunt-fish & 20 & Subsistence; Recreation \\
Harvest & 17 & Subsistence \\
Outdoor activity & 13 & Recreation \\
Homestead, household & 15 & \\
Access & & \\
Family & & \\
All others & & \\
Total & & \\
\hline
\end{tabular}

friends. Notably, of all the landscape values, recreation had the highest percentage of participants who wrote nothing down when asked why they valued this place. Recreation intersected with several other landscape values, such as "esthetic," "subsistence," and "social."

\section{Economic}

We found 33 thematic codes associated with the landscape value "economic" (Table 3). The most common theme was related to forest products, as a Lake Quinault participant discussed. "All the timberland should be considered for some kind of logging and wood cutting. This could provide livelihood for current and future residents in the logging industry and firewood for home. This would allow more residents to stay in Quinault and work here." The tourism industry was also frequently mentioned. According to a Port Angeles participant, "The trails also provide a healthy 
opportunity for tourists and locals." From Forks: "Dispersed recreation; contributes to healthy national economy." Embedded within many descriptions is the integrated idea of "making living/making a life." One Lake Quinault participant shared, "Five generations of my family have managed to survive off of the natural resources that these lands have provided us." A Port Townsend participant added, "This is where I earn a living, making everything else possible. This is where I express myself through my work, taking pride in my life's work, satisfaction in providing a service that others enjoy." Tied into the economic value is the forest's ability to provide food and resources used by households for everyday life, such as forage, firewood, fish and game. A Lake Quinault participant explained, "[I] used to work in the area; lots to explore; forage, etc. ... My stomping grounds." A Forks participant stated, "This is where I work, hunt, fish, ride my quad, hike, explore, camp and must more." The economic value appears to be an encompassing term that captures many ways people earning a living, create a life, form a community, and connect to the landscape over the course of multiple generations. The landscape value "economic" includes values of "social," "subsistence" and "recreation" and "home."

\section{Esthetic}

We found 32 thematic codes associated with "esthetic" (Table 4). "esthetic" was one of the more consistent landscape values in the typology. Most respondents focused on natural beauty, scenery, the panoramic vista or "killer views." A Port Angeles participant described a favorite place: "It is 'at the end of the earth,' and its impact is dramatic and awe-inspiring. You can stand there and literally feel the power of water against rocks." While visual beauty was the predominant theme, some focused on other senses, as exemplified by this participant from Aberdeen, "Standing where the ocean meets the land is both humbling and invigorating. The sounds, smells, the sea life and shorebirds, all play into the experience." For many, the ability to view wildlife was an important component of the 'view.' A Hoodsport participant described viewing the Hood Canal, "The clear water-no or very little industrial intrusion, the seafood that is abundant; the mammals that show up here and there." Water features and the ocean were also mentioned. As a Lake Quinault attendee explained, "I love the beauty of the lake. It is something I enjoy looking at every time I go by it." The value "esthetic" was often used to describe unique natural features, such as waterfalls, as well as places that were "wild" or "unspoiled." The narratives often included references to outdoor activities, suggesting that recreation sites may be selected for their scenic qualities. A Quilcene participant described her place, "[It's a] great place for outdoor activities, beautiful scenery."
Table 4 Top 10 codes and associated landscape values for "Esthetic," "Home," and "Heritage"

\begin{tabular}{|c|c|c|}
\hline Code name & Frequency & Associated landscape values \\
\hline \multicolumn{3}{|l|}{ Esthetic } \\
\hline Beauty & 41 & Esthetic \\
\hline Special feature & 27 & \\
\hline Outdoor activity & 25 & Recreation \\
\hline Scenery & 21 & Esthetic \\
\hline Wildlife & 18 & Environmental quality \\
\hline Peaceful & 14 & Health \\
\hline Wild & 13 & Wilderness \\
\hline Access & 12 & \\
\hline Water & 10 & Environmental quality \\
\hline History and tradition & 9 & Heritage \\
\hline All others & 95 & \\
\hline Total & 285 & \\
\hline \multicolumn{3}{|l|}{ Home } \\
\hline Homestead, household & 55 & Home \\
\hline Family & 36 & Social \\
\hline Work & 19 & Economic \\
\hline Property & 18 & Home \\
\hline Hunt-fish & 14 & Subsistence; Recreation \\
\hline Outdoor activity & 12 & Recreation \\
\hline Farm food & 12 & Subsistence \\
\hline Harvest & 12 & Subsistence \\
\hline Community & 11 & Social \\
\hline Scenery & 8 & Esthetic \\
\hline All others & 65 & \\
\hline Total & 276 & \\
\hline \multicolumn{3}{|l|}{ Heritage } \\
\hline History and tradition & 17 & Heritage \\
\hline Family & 15 & Social \\
\hline Outdoor activity & 11 & Recreation \\
\hline Work & 9 & Economic \\
\hline Culture & 8 & Heritage \\
\hline Homestead, house & 8 & Home \\
\hline Scenery & 8 & Esthetic \\
\hline Tourism & 7 & Economic; Recreation \\
\hline Social interaction & 6 & Social \\
\hline Education & 5 & Learning \\
\hline All others & 33 & \\
\hline Total & 127 & \\
\hline
\end{tabular}

Another theme that featured in the places labeled for their esthetic value was the ability to access these locations easily. "Beautiful and close to home." The landscape value "esthetic" overlaps with the values of "recreation," "environmental quality" and "wilderness." 


\section{Home}

Some 36 thematic codes were used for descriptions assigned to the landscape value "home" (Table 4). Some respondents interpreted "home" quite literally, placing dots or small circles around their homestead. Others drew large shapes around areas that might include entire valleys or even the entire peninsula. Qualitative analysis showed that participants referred to home both as a physical place, including property, outbuildings, house, and farm, and as an abstraction, with ties to social identity, history, and lineage. A Lake Quinault participant stated, "We built our home with our seven kids and our own hands. It is beautiful." Many descriptions emphasized the process of building homes in their descriptions. Home also was associated with memory and connection. An Aberdeen participant described their home by a river: "I live near the mouth and walk often in this area. So many memories are attached to various points along the waterway - it becomes tied to or woven with my identity and life in this community." Others described psychological aspects: "It's where I feel safe and at rest." A Lake Quinault added, "Beautiful, quiet, peaceful. A real sense of being home. I feel attached to this valley and to MY land." Family was also critical to the conceptualization of home, with many references to raising children, hosting grandchildren, and ties to previous generations. Other themes associated with home included work, hunting and fishing, and harvesting foods (in gardens as well as harvest of forest foods.) A Lake Quinault participant explained, "It's where I worked and raised my family. I want my family, grandkids and great grandchildren to experience the same way of good and clean life as I have done over the years." For a Port Townsend respondent: "This is my home; where I share my views of a lifetime partnership with my wife, where we relax and unwind, love our animals, share with friends, mark the turn of the seasons and the passage of time." The value "home" overlaps with "economic," "subsistence," and "social."

\section{Heritage}

The content analysis resulted in 26 thematic codes for descriptions assigned to the value "heritage" (Table 4). "Heritage" was often used to describe places of historic significance, and was commonly attached to historic lodges and homesteads erected by early settlers or recreation facilities constructed by the Civilian Conservation Corp. "Heritage" was used to describe places of cultural significance for Native Americans. A Quilcene participant said, "Historical sites of Quinaults; a true unvarnished image of a culture." Heritage was used to describe sites of archeological significance, such as petroglyphs and areas such as prairies, maintained by Native people for centuries. As a
Port Angeles participant explained, "The archaeological find changed what we know about the prehistory of high altitude use on the Olympic Peninsula." Heritage sometimes referred to natural history of an area, which often was integrated to cultural history. A Port Townsend attendee explained, "I spent several years researching the history (natural and cultural) of the dam, native people, river, salmon, etc." Finally, the value "heritage" captured a sense of shared family or personal history. Respondents described memories or repeated visits to areas with family elders. As this resident explained, “... My husband grew up at Lake Quinault and his family has a long history in the area; my family camped, fished and swam at Lake Quinault from the time we were small. My sister and I worked at the resort." Responses labeled as 'heritage' closely resembled the definition in the typology and there were some overlaps with "social," "recreation," "economic," and "learning,"

\section{Environmental quality}

We used 20 thematic codes for descriptions assigned to "environmental quality" (Table 5). Codes were highly consistent among respondents. One respondent from Shelton captures this variety, "I have been hiking in an exploring the Dosewallips watershed since 1970. Much of the watershed is in pristine condition, important for fish, animals, native plants, and water quality in Hood Canal." Many used "environmental quality" as a frame for shoreline ecology. Perceptions of natural beauty were often associated with "environmental quality" which suggests a connection between perceptions of ecological health and esthetics. Economic values appeared in association with environmental quality which suggests a link between environmental health and economic well-being. Finally, many discussed environmental quality as part of their outdoor activities. [It's a] "Wonderful habitat for wintering birds; a great place to camp and walk." Responses for "environmental quality' closely suggested overlaps with "esthetic," "recreation," and "wilderness."

\section{Spiritual}

We used 27 thematic codes for the landscape value 'spiritual' (Table 5). Participants relied on the landscape value of 'spiritual' to describe a unique relationship with a special place. These places may evoke sentiments of religiosity, tribal connection, the power of Nature, family ancestry, or protection, but the common theme was a connection to something grander than themselves. Qualitative coding for the value "spiritual" showed that it was commonly associated with special landscape features, (e.g., waterfalls, hot springs, tide-pools). Natural wonders appeared to elicit a feeling of nature as a power that transcended individual 
Table 5 Top 10 codes and associated landscape values for "Environmental Quality," "Spiritual," and "Social"

\begin{tabular}{|c|c|c|}
\hline Code name & Frequency & Associated landscape values \\
\hline \multicolumn{3}{|l|}{ Environmental quality } \\
\hline Wildlife & 8 & Environmental quality \\
\hline Beach & 8 & Environmental quality \\
\hline Beauty & 7 & Esthetic \\
\hline Water & 5 & Environmental quality \\
\hline Outdoor activity & 5 & Recreation \\
\hline Special feature & 5 & \\
\hline Ecosystems & 3 & Environmental quality \\
\hline Plant habitat & 3 & Environmental quality \\
\hline Agriculture & 3 & Economic \\
\hline Wild & 3 & Wilderness \\
\hline All others & 13 & \\
\hline Total & 63 & \\
\hline \multicolumn{3}{|l|}{ Spiritual } \\
\hline Special feature & 12 & \\
\hline Family & 10 & Social \\
\hline Relaxation & 9 & Health \\
\hline Beauty & 9 & Esthetic \\
\hline Higher power & 8 & Spiritual \\
\hline Water & 5 & Environ. Quality \\
\hline Outdoor activity & 5 & Recreation \\
\hline Emotional health & 4 & Health \\
\hline Social interaction & 3 & Social \\
\hline Hunt-fish & 3 & Subsistence; Recreation \\
\hline Symbolic & 3 & Intrinsic \\
\hline Peaceful & 3 & Emotional health \\
\hline Homestead, house & 3 & Home \\
\hline Steward & 3 & \\
\hline All others & 17 & \\
\hline Total & 97 & \\
\hline \multicolumn{3}{|l|}{ Social } \\
\hline History and tradition & 9 & Heritage \\
\hline Social interaction & 8 & Social \\
\hline Family & 7 & Social \\
\hline Culture & 7 & Heritage \\
\hline Outdoor activity & 6 & Recreation \\
\hline Homestead, house & 5 & Home \\
\hline Community & 4 & Social \\
\hline Access & 3 & \\
\hline Identity & 3 & Social \\
\hline All others & 6 & \\
\hline Total & 58 & \\
\hline
\end{tabular}

human experience. As one participant explained, "Hot springs are God's way of helping us reset our thermostats; primitive wilderness." Another described, "a mysterious place - the natural kettles intrigue me - I camped here when
I just arrived and loved having the deer and other wildlife visit our camp. I feel connected to God here." Spiritual also was used to describe strong connection with Native spirituality. Mt Olympus was noted as the, "home of Thunderbird; a tribal spiritual place." The ability to connect with the natural world in a spiritual way also was noted. "I love to walk the beach. I lose myself in the crashing waves, the wind, the birds, etc." The next most common theme related to family and the memory of ancestors. One mentioned a river valley as a sacred ground, "Family and historic cemeteries-regard as absolute sacred ground." Others noted locations where a deceased family member is remembered. "My father's ashes are scattered in a beautiful place." Another emerging theme was stewardship. A Port Angeles offered, "This is my family's home/cabin. I have learned much about natural history by observing the plants and animals and river over 35 years. I taught my children about those things too. We act as stewards of the river and forest." In addition to "heritage," the value "spiritual," appears to have commonalities with "health."

\section{Social}

We assigned 14 thematic codes to the landscape value 'social,' which was the fewest in the study (Table 5). Many of the sites labeled as social were described in a way to evoke historical or cultural meaning. For example, one person described their connection to an historic fort, "Great place for a group of friends to stay and enjoy! It has heritage and beauty! It's an opportunity to see history in the past." Social also was used to describe places where respondents engaged in activities with friends or family. For one participant, an historic lodge was associated with social qualities, "It is a favorite place to gather with friends on a summer afternoon, have a beer and enjoy the ever-changing weather." Another participant talked about a particular forest as an important part of their family history, "It provides a multitude of activities-it is part of my history. My grandparents call it home and so do I, as well. It is my primary horseback riding location and my husband's primary ATV/motorcycle location." The value of social also was applied to places which suggested a strong connection to home or to a sense of community. One person said about their community, "Port Townsend is for me, a very special place. A beautiful setting and full of great people and activities." As a landscape value, "social" appeared to be most discrete. Overlaps occurred with "heritage," "recreation," and "home."

\section{Wilderness}

We applied 20 thematic codes to the value "wilderness" (Table 6). Descriptions emphasized the features of wild, 
Table 6 Top 10 codes and associated landscape values for "Wilderness," "Subsistence," "Intrinsic"

\begin{tabular}{|c|c|c|}
\hline Code name & Frequency & Associated landscape values \\
\hline \multicolumn{3}{|l|}{ Wilderness } \\
\hline Wild & 8 & Wilderness \\
\hline Beauty & 7 & Esthetic \\
\hline Special feature & 5 & \\
\hline Access & 4 & \\
\hline Scenery & 4 & Esthetic \\
\hline Ecosystem & 3 & Environmental quality \\
\hline Challenge & 3 & Health \\
\hline Wildlife & 3 & Environmental quality \\
\hline Symbolic & 3 & Intrinsic \\
\hline Water & 3 & Environmental quality \\
\hline All others & 15 & \\
\hline Total & 58 & \\
\hline \multicolumn{3}{|l|}{ Subsistence } \\
\hline Forest Food & 9 & Subsistence \\
\hline Harvest & 8 & Subsistence \\
\hline Overall economy & 6 & Economic \\
\hline Farm food & 5 & Subsistence \\
\hline Homestead, house & 4 & Home \\
\hline Beach Food & 3 & Subsistence \\
\hline Community & 3 & Social \\
\hline Family & 3 & Social \\
\hline Hunt-fish & 3 & Subsistence; Recreation \\
\hline Agriculture & 3 & Economic \\
\hline All others & 19 & \\
\hline Total & 66 & \\
\hline \multicolumn{3}{|l|}{ Intrinsic } \\
\hline Beauty & 9 & Esthetic \\
\hline Special features & 4 & \\
\hline Wild & 4 & Wilderness \\
\hline Family & 3 & Social \\
\hline Outdoor activity & 3 & Recreation \\
\hline History and tradition & 2 & Heritage \\
\hline Scenery & 2 & Esthetic \\
\hline Water & 2 & Environmental quality \\
\hline All others & 12 & \\
\hline Total & 41 & \\
\hline
\end{tabular}

unadulterated landscapes with minimal signs of human encroachment. One participant described their place in this way: "It is raw beauty. In some places it appears totally untouched." Another described their favorite place as a "wild area to explore without trails." Places valued for wilderness often were associated with esthetics and with special natural features. "It is an isolated hike with river crossings and wild strawberry meadows, deep swimming holes, and wooded glens. So much variety and so private. It is like my own special place." Remoteness, solitude, and privacy were sometimes mentioned, but to a lesser extent than accessibility. As one person explained: "Right out the back door and you can be deep into nature. A great asset for the region." Another noted: "Beautiful watersheds, diverse ecology; easy access for large population to appreciate." Wilderness is not exclusively associated with wild, untrammeled places far off the beaten path, suggesting that for some, a place can be both wild and close to home. "Wilderness" closely aligned with the values "esthetic," and "environmental quality."

\section{Subsistence}

We used 20 thematic codes for the primary value "subsistence" (Table 6). There was consistency in the emphasis on food as a necessity, the ability to harvest food, and on hunting and fishing both as a source of food and as a traditional use. Hiking and fishing are viewed as recreation activities by some, and as life-sustaining activities by others. As a Quilcene participant described, "The Hood Canal provides wonderful food for our family and friends. We enjoy the seafood immensely." Many of the descriptions for places labeled as subsistence also emphasized economics. "Local food, supports local heritage, economy, provides important viewshed/rural character (tourism), salmon habitat." Moreover, the link between economic activity and family was often noted. One respondent noted, "The tree farm and oyster farm has been in our family since 1880, six generations now." Places marked subsistence also were described as being strongly connected to home. One explained, "It is where I live. It is where my family lives." Moreover, family was mentioned often in the descriptions of places that were valued for subsistence. A participant described a favorite as, "The best dewberry patch ever!! My daughters and I picked it every year until they grew up!" "Subsistence" shared overlaps with the values "economic," "social," and "recreation."

\section{Intrinsic}

Content analysis unearthed 20 thematic codes for descriptions assigned to the landscape value "intrinsic" (Table 6). "Intrinsic" was a value not frequently used and not uniformly understood. By far, the most common theme related to the use of intrinsic was natural beauty (esthetic). This value was used in describing a Pacific beach, "Beautiful setting with islands and needles just off shore." Similarly, Lake Ozette was valued "For its beauty, naturalness, and Native American heritage." Other themes that emerged from content analysis dealt with special or unique landscape features (e.g., waterfall, arch) or places perceived to be wild. Sometimes, intrinsic seemed to be used to describe places 
that were of symbolic importance or as scenery, but perhaps were not visited. One person from Hoodsport noted the Brothers Peaks, saying, "It is the dominant feature over our home area." Finally, a Shelton participant enjoyed her favorite place simply, "Because it is there." In addition to "esthetic" and "wilderness," "intrinsic" was associated with "environmental quality."

\section{Future}

The content analysis of "future" resulted in 14 thematic codes (Table 7). Future was rarely applied as a primary landscape value, but there was consistency between qualitative explanations and the value as it was defined in the typology. It often referred to the ability for future generations to visit a particular place for outdoor recreation, to harvest resources, to share with family, and to carry on a tradition. It also was used for special places like Olympic National Park, which people wanted to see preserved for the future. It also was applied to places visited for recreation and subsistence by multiple generations. In some cases, the value of "future" was used to share a political message about the perceived encroachment of federal lands. As one person from Lake Quinault said, "I go to school in Lake Quinault and when I graduate, if the Wild Olympics [movement] do not take over my home or school." Many places were associated with their ability to maintain resources, livelihoods, and lifestyles for future generations, but the respondents did not always utilize the landscape value of "future."

\section{Learning}

For "learning" 15 thematic codes were used (Table 7). Learning also was very seldom used as a primary value in the data set, even though references to discovery, exploration, and education were frequent. Learning was most commonly applied to natural history, but also occasionally to cultural history. As one participant noted: "[It] offers numerous opportunities to learn about the natural world $\&$ ways to sustain it." For one participant, learning seemed to involve social qualities and stewardship. "A place to find community and work together in the outdoors." Some participants talked specifically about environmental education for youth, in some cases related to economic history and harvest, such as shellfish farms, and in other cases related to natural features, such as tide-pools.

\section{Health}

In the content analysis, 16 thematic codes were used for "health" (Table 7). This landscape value was seldom used as a primary value, even though many passages talk about
Table 7 Top 10 codes and associated landscape values for "Future," "Learning," "Health"

\begin{tabular}{|c|c|c|}
\hline Code name & Frequency & Associated landscape values \\
\hline \multicolumn{3}{|l|}{ Future } \\
\hline Outdoor activity & 7 & Recreation \\
\hline Family & 6 & Social \\
\hline Beauty & 4 & Esthetic \\
\hline History and tradition & 4 & Heritage \\
\hline Presence & 3 & Intrinsic \\
\hline Farming & 3 & Economic \\
\hline General future & 2 & Future \\
\hline Scenery & 2 & Esthetic \\
\hline Wild & 2 & Wilderness \\
\hline Special Features & 2 & \\
\hline All others & 4 & \\
\hline Total & 39 & \\
\hline \multicolumn{3}{|l|}{ Learning } \\
\hline Education & 3 & Learning \\
\hline Access & 2 & \\
\hline Ecosystem & 2 & Environmental quality \\
\hline Natural history & 2 & Environmental quality \\
\hline Special feature & 2 & \\
\hline Youth & 2 & Social \\
\hline All others & 9 & \\
\hline Total & 22 & \\
\hline \multicolumn{3}{|l|}{ Health } \\
\hline Physical health & 4 & Health \\
\hline Nature connection & 3 & Spiritual \\
\hline Family & 3 & Social \\
\hline Beauty & 2 & Esthetic \\
\hline Peaceful & 2 & Health \\
\hline Outdoor activity & 2 & Recreation \\
\hline All others & 10 & \\
\hline Total & 26 & \\
\hline
\end{tabular}

fitness, well-being, relaxation, balance, and other states of being that suggest health. When 'health' was applied, it most often referred to physical health or fitness benefits of a place. Emotional health was not described explicitly, although some spoke of a place as being "peaceful" or an ideal place to "escape" or "relax." Family appeared to be an important component of health. One example of emotional health was provided by this Quilcene respondent, "My family relies on this location and our time there for balance and centeredness." A Port Townsend participant connected health with a clean environment and a desire for future generations to enjoy the area, "Healthy living, clean environment, future quality of life for my children and grandchildren." The biggest overlaps are with "spiritual" and "social." 
Fig. 3 Common thematic codes used across all 14 landscape values

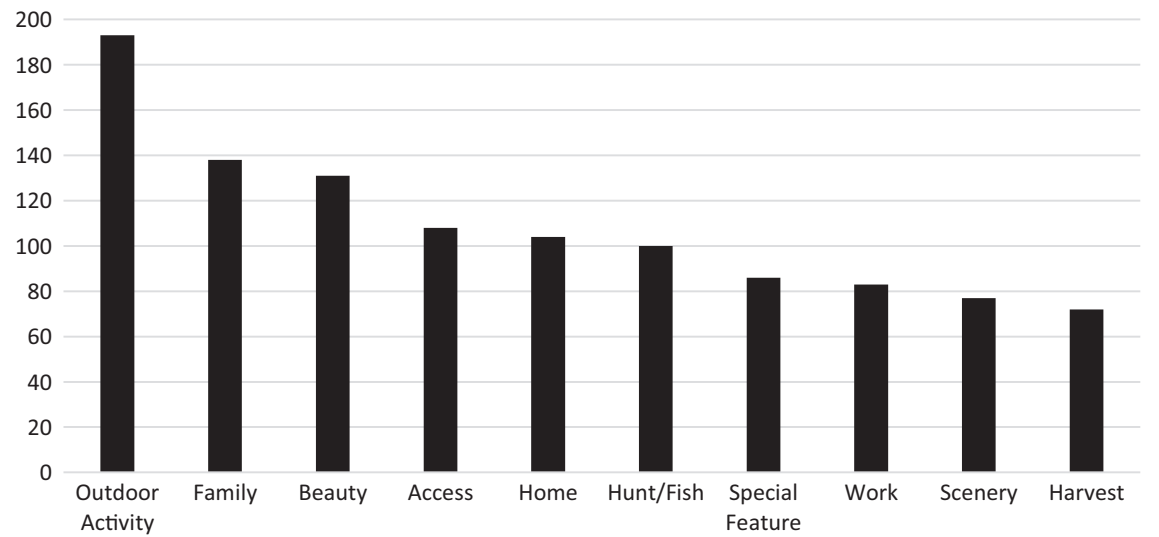

\section{Cross-cutting themes}

Thematic coding allows us to better understand how respondents perceive each individual landscape value, to assess the efficacy of each landscape value, and to potentially identify emerging values. Fig. 3 shows the top 10 thematic codes for all landscape values combined. There is some consistency in the top thematic codes with the most prominent landscape values earlier identified. "Outdoor activity" was the most common theme identified by the qualitative data, echoing the landscape value "recreation." Other thematic codes that echo high-frequency landscape values include: "beauty" and "scenery" (components of the value "esthetic"), "homestead/house" (contained within the value "home"), and "work," (a component of the value "economic"). "Subsistence" was not as frequently mentioned as a primary landscape value, but two thematic codes ("hunt/fish" and "harvest") suggest that subsistence may be more important than initially conveyed. Hunting and fishing can include elements of both "recreation" and "subsistence." "Economic" was identified as important as a primary landscape value, but was less prominent as a cross-cutting theme in the qualitative analysis.

In addition to affirming our set of landscape values, coding of qualitative text draws attention to meaningful threads that perhaps eluded our landscape values list. Three thematic codes emerged in the top-10 list that were not fully reflected in the landscape values typology: "family," "access," and "special feature." "Family" appeared as a thematic code in qualitative responses for every landscape value, with highest frequency in the values "home," "recreation," "heritage," and "economic." Places on the peninsula were not just important because they provided a place to play, work, or forage, but they were a place for families to congregate and connect in different ways. Respondents described passing down knowledge, traditions, and memories to children and grand-children. One participant explained, "Our seven children grew up loving this place. Our youngest daughter was conceived there."
Interestingly, the one value that would appear to best capture family connections (social) was not used as often, which may suggest that the term "social" does not adequately capture family relations.

Another theme that emerged from the qualitative analysis was "access."

"Access" was most commonly associated with landscape values of "recreation," "economic," and "esthetic."There were two elements to the theme of "access." The first was the ability of people to get to places quickly and easily from home or from the highway. For an Aberdeen participant, "This is a pleasant lake surrounded by hiking trails and logging roads; good for walks, runs, bike rides with friends. It is clearly enjoyed by many for camping and fishing-a good family area that offers a taste of the outdoors close to town. Accessible." Another meaning associated with access dealt with the participants' user rights, or their desire to maintain or expand their chosen use of site. There was a desire among some off-highway vehicle users to gain access to forest roads for specialized use. A Forks participant said, "We need to have better public access; use of off-road vehicles be available." Access was not a landscape value in this study, but thematic analysis revealed the importance of access to Olympic Peninsula residents.

Finally, "special feature" was used to describe recognition of a unique landscape attribute that was central in the decision to visit a site. A special feature may be a grove of old growth forest, a waterfall, a hot spring, a bountiful view, or prolific harvest area. One person described wildlife in the Quilcene Bay, "trumpeter swans, tidal flow, animals - otter, deer, and bobcats." A Hoodsport participant marveled about a "Spectacular waterfall-great place to view mountain goats." Another described a favorite prairie, as a "very rare plant community left over from last climate change." These descriptions relay the importance of the physical landscape. While "special landscape feature" is not a landscape value, it does raise questions about whether our landscape values approach may overshadow the importance of physical geography, weather, and biological properties that attract 
people to places. More attention to unique landscape features that characterize sites may be warranted.

Table 8 summarizes the 14 landscape values used in this study, showing how often each value was referenced, linkages between landscape values and place narratives, overlaps with other landscape values, emergent values, and general observations. This information draws attention to a few landscape values that are not universally understood, have multiple interpretations, or overlap in meaning with other values. The table offers a deeper understanding of each landscape value and any variations of meaning that may affect the way these data are interpreted by planners and decision makers. Several observations are warranted. Recreation was the most frequently mapped landscape value, yet, the qualitative responses reflected a diversity of meanings, as indicated by code frequency. Moreover, recreation narratives often described activities that are reflected in other landscape values (e.g., heritage, learning, socializing, and subsistence). Both "economic" and "home" also contained a wide variety of meanings (as indicated by code frequency). The themes of "home," "economic," "subsistence," "family," "heritage," and "community" were often interwoven in the qualitative responses; teasing out discrete values or differentiating their spatial attributes may be in some cases artificial. "Subsistence" is a landscape value that requires more exploration as it encompasses aspects of provisioning, recreation, culture, and family tradition. The landscape values "esthetic," "wilderness," and "social" showed a high degree of internal consistency with the narrative descriptions and a strong connection to the typology definition. The landscape values "wilderness" and "social" were more prominent as secondary values and seem to capture important human connections with the landscape. Several values ("esthetic," "wilderness," "environmental quality" and "spiritual") had a strong connection to the special landscape features and natural attractions. Several value in this study did not seem to resonate with participants and should be examined further. The value "health" may be problematic because it is difficult to associate with a physical space on the landscape and may be a derivative of other values. Perhaps the values "recreation" and "spiritual" are serving as proxies for "health." The value "intrinsic" was not frequently used and not well understood by respondents. Two values, "future" and "learning" were both infrequently used and had lower consistency in meaning among respondents.

\section{Discussion}

Our study approach emphasized respondent selection of a finite number of special places and the assignment of primary and secondary landscape values to those places from a fixed list of 14 predefined values. Our data gathering approach differs from earlier studies, where the respondent typically is not required to limit the number places selected and the emphasis is on the distribution of values across a landscape, with equal units available for each landscape value. Our study was interested in special places and the values and meanings Olympic Peninsula residents attached to those places, rather than the variety of values (benefits) a landscape provides. Our approach also emphasized the concurrent eliciting of qualitative explanations about the meaning of a particular place. This allowed us to make comparisons between how values were assigned and what the places actually signify to people living near them. It also allows us to dig deeper into the multitude of meanings associated with each landscape value and to detect any fuzziness or overlap in meanings among values. This may provide clues as to why certain landscape values were selected more readily. And, it offers methodological insights that may inform future applications of the landscape values typology.

Recreation dominated as the most important landscape value associated with special places in this study of Olympic Peninsula residents, which is consistent with previous studies of state managed forests and public lands in North America and Australia, (Brown and Reed 2009; Brown et al. 2014; Brown and Brabyn 2012; Nielsen-Pincus 2011; Raymond and Brown 2010; van Riper et al. 2012). Recreation, followed by "esthetics" topped the list of primary and secondary values participants assigned to their special places. These results confirm earlier studies that show that special places are co-located spatially with recreation, esthetic, economic, and spiritual values (Brown and Raymond 2007). On the surface, the preponderant use of "recreation" as a landscape value suggests that discretionary or leisure based outdoor activities are most valued by residents of this region. While "recreation" indeed may reflect the public's primary connection with their landscape, the widespread use of "recreation" as a value may result from other factors. Perhaps the methodology of selecting discrete places on the landscape lends itself to respondent's thinking primarily places used for recreation, rather than say logging, which occurs not in one specific place, but as a complex set of activities across the landscape (tree felling, sorting, transporting, milling). Or, perhaps the cognitive step of choosing from a finite list of landscape values creates conditions that favor the selection of "recreation" over other values because it is more concrete (object of value) compared to "spiritual" or "health," (abstract values) (Bengston and Xu 1995). The ubiquitous use of "recreation" also might be indicative of the fact that recreation embodies a diversity of activities making it a ready choice for "onestop values shopping." The methodological approached we utilized encouraged respondents to select a fairly limited 


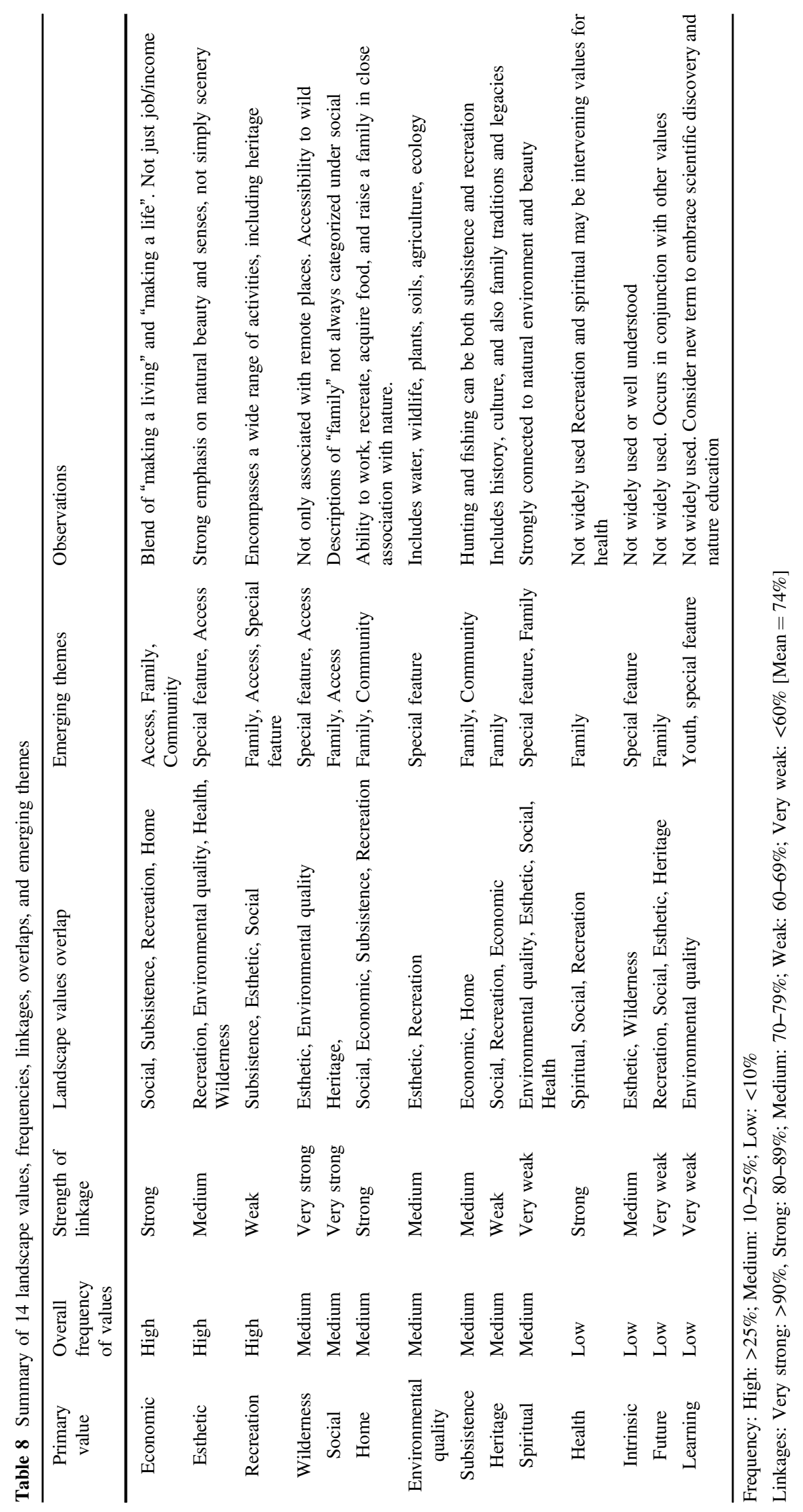


number of values. Recreation may have been viewed as a good option because it encompassed other values. Recreation also could be a proxy for other values, such as "health" and "learning." Our data showed overlaps with other values such as "heritage," "subsistence," and "social." It remains unclear whether recreation was popular because it accurately reflects the core "held" values of respondents or because it is easier to associate with a landscape (assigned value) (Rokeach 1973; Brown 1984). Questions about recreation and other dominant landscape values (i.e., "esthetic", "economic") caused us to explore the meanings associated with all landscape values. Interestingly, the array of dominant values unearthed in this study, which was conducted in a public meeting format, are quite similar to those gathered using surveys, which have less potential for social desirability bias.

When we looked at how people described the meaning of these special places in their own words and compared them with the landscape value assigned to those places, we found a high level of convergence. For $74 \%$ of primary landscape values applied, the qualitative explanation matched the value in its meaning or intent. This suggest that in most cases, applying one landscape value will capture at least some of the individual's sentiments about their special place. For the remaining $26 \%$ of cases, we wondered whether the mismatch between landscape values and narrative descriptions was related to differences in understanding or whether our list of landscape values was insufficient. Our explorations revealed that in cases of a mismatch, the secondary landscape values closed most of the gap. However, for a small percentage of special places, none of the values chosen matched the narrative description. Examination revealed that discrepancies may be due to either individual idiosyncrasies of respondents (who may not have fully grasped the instructions), or to what might be a propensity to want to expound on land management issues in the open-ended boxes. We also found variation among landscape values, with some values (wilderness, social) more consistently represented in the qualitative explanations than others, which may suggest that these landscape values are easier to talk about or think about. Meanwhile, "recreation," the highest frequency value identified in the study, was accurately reflected in the qualitative explanation about two-thirds of the time. The incongruence between landscape value assignment and the narrative description about the meaning of special places inspired our team to look more closely at the qualitative responses within each primary landscape value

Offering an open-ended query about people's connection with a special place allowed multiple values to surface and the connections between these values were more evident. Our content analysis of qualitative data elicited themes that indeed echoed landscape values featured in the typology; yet, we also identified under-utilized and emergent values. "Subsistence," was designated by just $3 \%$ of respondents as a primary value, but featured in the top-10 list of thematic codes from the qualitative analysis. Two themes unearthed in the qualitative content analysis ("family" and "access") did not appear in the landscape values typology. Although the landscape value, "social" includes family in its definition, it was not often used to describe family interactions. Qualitative analysis showed that "family" was woven into narratives of Olympic Peninsula residents for every primary landscape value in the typology. Raymond et al. (2010) also found family bonding an important component of place attachment in their study linking landscape values to special places. Exploration of "family" as a landscape value may be considered in future studies. We recognize that the assignment of a landscape value to a physical place is a different cognitive act from the task of describing the meaning of a place in your own words. While these are linked, the response provided in the open-ended format provided a more nuanced understanding of people's connection with place and draws our attention to what really matters at the core.

People assign meanings and attach values to landscapes through direct experiences as well as recounted renderings, such as stories, memories, and histories. Landscape values mapping uses spatial representations (maps, aerial photos) of physical landscapes to unearth those meanings. When conducted in a small group format, the mapping action is potentially influenced by the presence of other participants, or susceptible to social desirability bias. More research is needed to understand how the selection of a place on the map influences the landscape value assigned and the meanings described by individuals.

\section{Conclusion}

The landscape values typology originally validated and adopted by Brown and Reed (2000) has been used in PGIS studies in a wide variety of management contexts, spatial scales, and settings. The typology incorporates a set of values that are presumed to be discrete, clearly understood, and uniformly interpreted. When comparing primary landscape values assigned to a place with the actual narrative descriptions, we found some inconsistencies, suggesting that a particular place has multiple meanings; eliciting one value is not sufficient. The landscape value 'recreation' was most commonly selected, but also had the most overlapping meanings with other landscape values, which may be part of its appeal as a "catch-all" value. Two values emerged in the analysis that are not standards in the landscape values typology (family and access), and deserve future consideration. Including a qualitative component to landscape 
values mapping adds additional depth and understanding both of what a particular place means to the respondent and also how that person is interpreting the landscape value construct. The landscape values typology continues to be useful in capturing diverse and overlapping landscape benefits across a broad area. Taken alone, it may not be sufficient to render the complex array of sentiments, experiences, and symbolic attachments associated with a particular place. The inclusion of complementary tools that evoke narrative descriptions of place attachments and meanings is recommended. Our study involved systematic qualitative analysis of one data set and findings cannot be generalized beyond this study.

Acknowledgements Funding for this project was provided by USDA-Forest Service, PNW Research Station under Joint Venture Agreement PNW 08-JV-11261985-177. We thank residents of the Olympic Peninsula who participated in our community events and shared stories, relayed memories and described their unique connections with special places throughout the region. We appreciate the support of the Olympic National Forest leadership team, who inspired this study and we hope that our results prove useful to them. We thank many people involved in aspects of this project, including Diane Besser, Melissa Poe, David Banis, Laysa Rodrigues, Leilan Greer, and Kathy LaPlante. Finally, we appreciate the thoughtful reviews of this manuscript.

Ethical Approval All procedures performed in studies involving human participants were in accordance with the ethical standards of the institutional and/or national research committee and with the 1964 Helsinki declaration and its later amendments or comparable ethical standards.

Informed Consent Informed consent was obtained from all individual participants included in the study.

\section{Compliance with Ethical Standards}

Conflict of Interest The authors declare that they have no competing interests.

\section{References}

Alessa L, Kliskey A, Brown G (2008) Social-ecological hotspots mapping: a spatial approach for identifying coupled social-ecological space. Landsc Urban Plan 85(1):27-39

Ardoin NM (2014) Sense of place and environmental behavior at an eco-regional scale in three sites. Hum Ecol 42(3):425-441

Bengston DN, Fan DP, Celarier DN (1999) A new approach to monitoring the social environment for natural resource management and policy: the case of US national forest benefits and values. J Environ Manage 56(3):181-193

Bengston DN, Xu Z (1995) Changing national forest values: A content analysis. St. Paul, MN: US Dept. Agric, Forest Service, North Central Forest Experimental Station, Research Paper NC-323

Besser DT, McLain R, Cerveny LK, Biedenweg K, Banis D (2014) Mapping landscape values: issues, challenges and lessons learned from fieldwork on the Olympic Peninsula, Washington. Environ Practice 16(2):138-150

Beverly JL, Uto K, Wilkes J, Bothwell P (2008) Assessing spatial attributes of forest landscape values: an internet-based participatory mapping approach. Can J Forest Res 38(2):289-303

Brown G (2004) Mapping spatial attributes in survey research for natural resource management: methods and applications. Soc Nat Resour 18(1):17-39

Brown G (2006) Mapping landscape values and development preferences: a method for tourism and residential development planning. Int J Tourism Res 8(2):101-113

Brown G (2008) Social-ecological hotspots mapping: a spatial approach for identifying coupled social-ecological space. Landsc Urban Plan 85(1):27-39

Brown G (2012) Public participation GIS (PPGIS) for regional and environmental planning: reflections on a decade of empirical research. J Urban Reg Inf Syst Assoc 25(2):7-18

Brown G (2017) A review of sampling effects and response bias in internet participatory mapping (PPGIS/PGIS/VGI). Transactions GIS 21(1):39-56

Brown G, Alessa L (2005) A GIS -based inductive study of wilderness values. Intern J Wilderness 11(1):14-18

Brown G, Brabyn L (2012) An analysis of the relationships between multiple values and physical landscapes at a regional scale using public participation GIS and landscape character classification. Landscape Urban Plan 107(3):317-331

Brown G, Donovan S (2014) Measuring change in place values for environmental and natural resource planning using public participation GIS (PPGIS): results and challenges for longitudinal research. Soc Nat Resour 27:36-54

Brown G, de Bie K, Weber D (2015) Identifying public land stakeholder perspectives for implementing place-based land management. Landsc Urban Plan 139:1-15

Brown G, Fagerholm N (2015) Empirical PPGIS/PGIS mapping of ecosystem services: a review and evaluation. Ecosyst Serv 13:119-133

Brown G, Hausner V, Lægreid E (2015) Physical landscape associations with mapped ecosystem values with implications for spatial value transfer: an empirical study from Norway. Ecosyst Serv 15:19-34

Brown G, Kelly M, Whitall D (2014) Whose public? Sampling effects in public participation GIS and volunteered geographic information (VGI) systems for public lands management. J Environ Plan Manage 57(2):190-214

Brown G, Kyttä M (2014) Key issues and research priorities for public participation GIS (PPGIS): a synthesis based on empirical research. Appl Geogr 46:122-136

Brown G, Montag JM, Lyon K (2012) Public participation GIS: a method for identifying ecosystem services. Soc Nat Resour 25 (7):633-651

Brown G, Raymond C (2007) The relationship between place attachment and landscape values: toward mapping place attachment. Appl Geogr 27(2):89-111

Brown G, Raymond CM (2014) Methods for identifying land use conflict potential using participatory mapping. Landsc Urban Plan 122:196-208

Brown G, Reed P (2000) Validation of a forest values typology for use in national forest planning. For Sci 46(2):240-247

Brown G, Reed P (2009) Public participation GIS: a new method for use in national forest planning. For Sci 55(2):166-182

Brown G, Smith C, Alessa L, Kliskey A (2004) A comparison of perceptions of biological value with scientific assessment of biological importance. Appl Geogr 24(2):161-180

Brown G, Weber D (2012) Measuring change in place values using public participation GIS (PPGIS). Appl Geogr 34:316-324 
Brown G, Weber D (2011) Public participation GIS: a new method for national park planning. Landsc Urban Plan 102(1):1-15

Brown G, Weber D, de Bie K (2015) Is PPGIS good enough? An empirical evaluation of the quality of PPGIS crowd-sourced spatial data for conservation planning. Land Use Policy 43:228-238

Brown TC (1984) The concept of value in resource allocation. Land Econ 60:231-245

Buttolph LP, Kay W, Charnley S, Moseley C, Donoghue EM (2006) Northwest Forest Plan-the first 10 years: socioeconomic monitoring of the Olympic National Forest and three local communities. Gen Tech Rep PNW-GTR-679. Portland, OR: U.S. Department of Agriculture, Forest Service, Pacific Northwest Research Station. p 84

Cheng AS, Kruger LE, Daniels SE (2003) "Place" as an integrating concept in natural resource politics: propositions for a social science research agenda. Soc Nat Resour 16(2):87-104

Clement JM, Cheng AS (2011) Using analyses of public value orientations, attitudes and preferences to inform national forest planning in Colorado and Wyoming. Appl Geogr 31(2): 393-400

Fish R, Church A, Willis C, Winter M, Tratalos JW, Haines-Young R, Potschin M (2016) Making space for cultural ecosystem services: insights from a study of the UK nature improvement initiative. Ecosyst. Serv 21:329-343

Fagerholm N, Kayhko N, Ndumbaro, F, Khamis M (2012) Community stakeholders' knolwedge in landscape assessments Mapping indicators for landscape servies. Ecol Indic 18: 421-33

Gustafson P (2001) Meanings of place: everyday experience and theoretical conceptualizations. J Environ Psychol 21:5-16

Ives CD, Kendal D (2014) The role of social values in the management of ecological systems. J Environ Manage 144:67-72

Kenter JO, Reed MS, Fazey I (2016) The deliberative value formation model. Ecosyst Serv 21:194-207

Kenter JO, O'Brien L, Hockley N, Ravenscroft N, Fazey I, Irvine KN, Reed MS, Christie M, Brady E, Bryce R, Church A (2015) What are shared and social values of ecosystems? Ecol Econ 111:86-99

Kil N, Holland SM, Stein TV (2014) Place meanings and participatory planning intentions. Soc Nat Resour 27(5):475-491

Lien C (1991) Olympic battleground: the power politics of timber transformation. Random House, New York, NY

Lockwood M (1999) Humans valuing nature: synthesizing insights from philosophy, psychology, and economics. Environ Value 8:381-401

McLain R, Cerveny L, Besser D, Banis D, Biedenweg K, Todd A, Kimball-Brown C, Rohdy S (2013) Mapping human-environment connections on the Olympic Peninsula: an atlas of landscape values. Occasional Papers in Geography No. 7

Moore S, Brown G, Kobryn H, Strickland-Munro J (2017) Identifying conflict potential in a coastal and marine environment using participatory mapping. J Environ Manage. In press. http://www.la ndscapemap2.org/publications/JEMA_conflict-preprint.pdf

Nielsen-Pincus M (2011) Mapping a values typology in three counties of the interior Northwest, USA: scale, geographic associations among values, and the use of intensity weights. Soc Nat Resour 24(6):535-552

Rall E, Bieling C, Zytynska S, Haase D (2017) Exploring city-wide patterns of cultural ecosystem service perceptions and use. Ecol Indic 77:80-95

Ramirez-Gomez SOI, Brown G, Verweij PA, Boot R (2016) Participatory mapping to identify indigenous community use zones: implications for conservation planning in southern Suriname. J Natur Conserv 29:69-78
Raymond CM, Brown G (2010) Assessing spatial associations between perceptions of landscape value and climate change risk for use in climate change planning. Clim Change 104:653-678

Raymond CM, Brown G (2011) Assessing conservation opportuntiy on private land: Socio-economic, behavioral, and spatial dimensions. J Environ Manag 92 (10):2513-23

Raymond CM, Brown G, Weber D (2010) The measurement of place attachment: personal, community, and environmental connections. J of Environ Psychol 30(4):422-434

Raymond CM, Bryan BA, MacDonald DH, Cast A, Strathearn S, Grandgirard A, Kalivas T (2009) Mapping community values for natural capital and ecosystem services. Ecol Econ 68 (5):1301-1315

Raymond CM, Bryan BA, MacDonald DH, Cast A, Strathearn S, Grandgirard A, Kalivas T, Brown G, Raymond C (2007) The relationship between place attachment and landscape values: toward mapping place attachment. Appl Geogr 27(2):89-111

Raymond CM, Kenter JO (2016) Transcendental values and the valuation and management of ecosystem services. Ecosyst Serv 21:241-257

Reed P, Brown G (2003) Values suitability analysis: a methodology for identifying and integrating public perceptions of ecosystem values in forest planning. J Environ Plan Manage 46(5):643-658

Rokeach M (1973) The nature of human values. Free Press, New York, NY

Rolston H, Coufal J (1991) A forest ethic and multivalue forest management. J For 89:35-40

Scannell L, Gifford R (2010) Defining place attachment: a tripartite organizing framework. J Environ Psychol 30:1-10

Schultz PW, Gouveia VV, Cameron LD, Tankha G, Schmuck P, Franěk M (2005) Values and their relationship to environmental concern and conservation behavior. Journal Cross-Cult Psychol 36(4):457-475

Schwartz SH, Bilsky W (1987) Toward a universal structure of human values. J Pers Soc Psychol 53:550-562

Seymour E, Curtis A, Pannell D, Allan C, Roberts A (2010) Understanding the role of assigned values in natural resource management. Australas J Environ Manage 17 (3):142-153

Sherrouse BC, Clement JM, Semmens DJ (2011) A GIS application for assessing, mapping, and quantifying the social values of ecosystem services. Appl Geogr 31(2):748-760

Sieber R (2006) Public participation geographic information systems: a literature review and framework. Ann Assoc Am Geogr 96 (3):491-507

Stedman RC (2003) Is it really just a social construction? The contribution of the physical environment to sense of place. Soc Nat Resour 16(8):671-685

Stern PC, Dietz T (1994) The value basis of environmental concern. J Soc Issues 50(3):65-84

Tuan YF (1977) Space and place: the perspective of experience. University of Minnesota Press, Minneapolis, MN

Tyrväinen L, Mäkinen K, Schipperijn J (2007) Tools for mapping social values of urban woodlands and other green areas. Landsc Urban Plan 79(1):5-19

U.S. Census (2010) General population and housing characteristics. http://factfinder2.census.gov (August 2016)

van Riper CJ, Kyle GT, Sutton SG, Barnes M, Sherrouse BC (2012) Mapping outdoor recreationalists' perceived social values for ecosystem services at Hinchinbrook Island National Park, Ausralia. Appl Geog 35(1):164-73

Whitehead AL, Kujala H, Ives CD, Gordon A, Lentini PE, Wintle BA, Nicholson E, Raymond CM (2014) Integrating biological and social values when prioritizing places for biodiversity conservation. Conserv Biol 28(4):992-1003 
Williams DR, Stewart WP, Kruger LE (2013) The emergence of placebased conservation. In Stewart WP, Williams DR, Kruger L (eds) Place-based conservation, Springer, Netherlands, pp 1-17

Winter C (2005) Preferences and values for forests and wetlands: a comparison of farmers, environmentalists, and the general public in Australia. Soc Nat Resour 18(6):541-555

Yung L, Freimund WA, Belsky M (2003) The politics of place: understanding meaning, common ground, and political difference on the Rocky Mountain front. For Sci 49(6): $855-866$

Zhu X, Pfueller S, Whitelaw P, Winter C (2010) Spatial differentiation of landscape values in the Murray River region of Victoria, Australia. Environ Manage 45(5):896-911

Zube EH (1987) Perceived land use patterns and landscape values. Landsc Ecol 1(1):37-45 